\title{
Penyelesaian Persamaan Kadomtsev Petviashvili Menggunakan Metode Asimtotik
}

\author{
Laely Kurniasih ${ }^{1}$, Mashuri $^{2}$, Rina Reorita ${ }^{3}$ \\ 1,2,3 Jurusan Matematika, Fakultas MIPA, Universitas Jenderal Soedirman \\ Jl. Dr. Soeparno Kampus UNSOED Karangwangkal Purwokerto 53123 \\ Email: mashuri_unsoed@yahoo.com²
}

\begin{abstract}
ABSTRAK
Persamaan Kadomtsev Petviashvili (KP) adalah persamaan yang diusulkan oleh Boris Kadomtsev dan Vladimir Petviashvili tahun 1970. Persamaan ini merupakan persamaan gelombang dua dimensi. Dalam artikel ini, persamaan KP dengan gelombang satu arahnya adalah persamaan Korteweg de Vries (KdV) diturunkan dan diselesaikan menggunakan metode asimtotik, sebagai inputnya adalah gelombang monokromatik. Dalam artikel ini akan disimulasikan penjalaran gelombang monokromatik pada waktu tertentu untuk parameter-parameter gelombang yang ditetapkan.
\end{abstract}

Kata kunci: persamaan KP, persamaan KdV, metode asimtotik, gelombang monokromatik.

ABSTRACT

The Kadomtsev Petviashvili (KP) equation is an equation proposed by Boris Kadomtsev and Vladimir Petviashvili in 1970. This is a second dimention of wave equation. In this research, the KP equation that contain the Korteweg de Vries (KdV) equation as uni directional water wave is derived and solved by asymptotic method with monochromatic wave as a signal input. In this research will be simulated the traveling of monochromatic wave in certain time for parameters that we choose.

Keywords: equation, KdV equation, asymptotic method, monochromatic waves.

\section{Pendahuluan}

Gelombang merupakan gejala pemindahan usikan atau gangguan. Gelombang yang merambat hanya memindahkan energi saja, tanpa menggeser medium gelombangnya (Jati dan Priyambodo, 2008: 227). Salah satu contoh gelombang yang mudah diamati adalah gelombang air.Pemodelan perilaku gelombang air seperti air laut dibutuhkan agar dapat mengoptimalkan kegiatan yang berkaitan dengan kelautan seperti perkapalan, pembangunan lepas pantai, dan sebagainya.

Fenomena gelombang air pertama kali ditemukan oleh John Scott Russell, peneliti terkenal dari Inggris. Pada tahun 1834, dia meneliti gerakan dari perahu yang ditarik cepat oleh sepasang kuda di saluran air yang sempit. Pada saat perahu berhenti terjadi sebuah gelombang air yang tidak mengalami perubahan bentuk dan kecepatan selama perambatannya. Russel menamakan gelombang dalam fenomena tersebut adalah gelombang soliter. Penemuannya ini dilaporkan pada "British Association Reports" tahun 1844, akan tetapi Russel tidak dapat membuat perumusan matematika untuk fenomena tersebut dan dia juga tidak dapat membuat fisikawan percaya pada masa itu (Chaohao, 1995: 1).

Perumusan matematis yang dapat menjelaskan fenomena gelombang soliter pertama kali diajukan oleh Diederik Johanes Korteweg dan mahasiswanya Gustav de Vries tahun 1895. Persamaan yang diberi nama KdV (Korteweg de Vries) ini merupakan sebuah persamaan gelombang nonlinier yang menunjukkan gelombang yang panjang dan amplitudo kecil pada kondisi air yang dangkal (Chaohao, 1995: 1). Penelitian mengenai persamaan KdV sudah sering dilakukan, salah satunya penurunan persamaan KdV oleh Debnath (1994).Persamaan KdV diturunkan dari syarat kondisi dan syarat batas fluida pada umumnya.Banyak metode yang dapat digunakan untuk mencari solusi persamaan tersebut.Metode standar yang digunakan dalam mencari solusi persamaan nonlinier 
yaitu metode asimtotik (Marwan, 2006). Menurut Mashuri dan Marwan (2011) solusi persamaan $\mathrm{KdV}$ dapat didekati dengan menggunakan metode asimtotik dimana amplitudo diekspansikan dalam bentuk deret pangkat sampai orde ketiga.

Seiring berjalannya waktu, pemodelan persamaan gelombang air laut terus dikembangkan, tidak hanya dimodelkan dengan persamaan satu dimensi, persamaan gelombang dapat dimodelkan dengan persamaan dua dimensi. Generalisasi dari persamaan KdV atau sering disebut sebagai persamaan KdV dua dimensi dikenal sebagai persamaan KP (Kadomtsev Petviashvili). Persamaan ini ditemukan oleh Boris Kadomtsev dan Vladimir Petviashvili tahun 1970. Persamaan yang menggambarkan dua dimensi dari KdV ini lebih menarik untuk dikaji karena gelombang lebih menggambarkan gelombang air pada umumnya yang terlihat dalam bentuk dua dimensi. Persamaan KP yang akan digunakan dalam penelitian ini mengandung persamaan KdV yang diturunkan oleh Debnath (1994). Persamaan KdV yang diturunkan oleh Debnath merupakan persamaan KdV klasik. Penurunan persamaan KP yang di dalamnya mengandung persamaan KdV klasik termuat dalam jurnal Liam dan Groesen (2010). Penelitian mengenai persamaan KP tersebut masih jarang dilakukan.Oleh karena itu, penulis tertarik untuk menyelesaikan persamaan KP yang mengandung persamaan KdV klasik. Persamaan KP dapat diselesaikan secara analitik maupun numerik.Dalam penelitian ini penulis menyelesaikan persamaan KP secara analitik dengan menggunakan metode standar yang biasa digunakan dalam persamaan diferensial nonlinier yaitu metode asimtotik sampai orde ketiga.

\section{Metode Penelitian}

Metode yang digunakan dalam penelitian ini adalah studi pustaka dengan tahapan yang dilakukan adalah sebagai berikut:

1. Menurunkan persamaan KP yang diturunkan dari persamaan gelombang sederhana.

2. Menyelesaikan persamaan KP menggunakan metode asimtotik.

3. Menganalisa relasi dispersi yang diperoleh yakni relasi yang menghubungkan antara bilangan gelombang dengan kecepatan gelombang berjalan

4. Melakukan simulasi penyelesaian asimtotik persamaan KP menggunakan software Matlab 7.0.

\section{Hasil dan Pembahasan}

\subsection{Penurunan Persamaan KP}

Persamaan gelombang satu dimensi yang sederhana yaitu:

$$
\partial_{t}^{2} \eta=c_{0}^{2} \partial_{x}^{2} \eta
$$

dengan $\eta(x, t)$ menyatakan elevasi gelombang di permukaan pada posisi $x$ saat waktu $t$ dan $c_{0}$ menyatakan cepat rambat gelombang. Persamaan (1) menyatakan gelombang yang berjalan dua arah. Perhatikan persamaan gelombang yang berjalan ke arah $x$ positif

$$
\left(\partial_{t}+c_{0} \partial_{x}\right) \eta=0
$$

Solusi dari persamaan (2) yaitu

$$
\eta=a e^{i \theta}+c c
$$

dengan $a$ menyatakan amplitudo, $\theta=k x-\omega t, k$ menyatakan bilangan gelombang, $\omega$ menyatakan frekuensi, dan $c c$ menyatakan sekawan kompleks $\left(a e^{-i \theta}\right)$ serta relasi dispersinya yaitu $\omega=c_{0} k$. Persamaan gelombang dua dimensi yang sederhana adalah sebagai berikut

$$
\partial_{t}^{2} \eta=c_{0}^{2}\left(\partial_{x}^{2} \eta+\partial_{y}^{2} \eta\right) \text {. }
$$

dengan $\eta(x, y, t)$ menyatakan elevasi gelombang di permukaan pada posisi $(x, y)$ saat waktu $t$ dan $c_{0}$ menyatakan cepat rambat gelombang. Solusi dari persamaan (4) adalah

$$
\eta=a e^{i \theta}+c c
$$


dengan $a$ menyatakan amplitudo, $\theta=k x+l y-\omega t, k$ dan $l$ menyatakan bilangan gelombang dalam arah $x$ dan $y, \omega$ menyatakan frekuensi serta $c c$ menyatakan sekawan kompleks, serta relasi dispersinya yaitu

$$
\omega=c_{0} k \sqrt{1+\frac{l^{2}}{k^{2}}} .
$$

Menurut Liam dan Groesen (2010), gelombang multi arah yang berjalan pada arah $x$ positif akan mempunyai $l<<k$ (bilangan gelombang di arah $y$ jauh lebih kecil dengan bilangan gelombang di $\operatorname{arah} x$ ).Dengan demikian, relasi dispersinya yaitu

$$
\omega \approx c_{0}\left(k+\frac{1}{2} \frac{l^{2}}{k}\right)
$$

Persamaan (7) sesuai dengan persamaan berikut

$$
\partial_{x}\left(\partial_{t} \eta+c_{0} \partial_{x} \eta\right)+\frac{c_{0}}{2} \partial_{y}^{2} \eta=0 .
$$

Persamaan (8) merupakan persamaan KP dua dimensi yang memuat persamaan gelombang satu arah yang sederhana. Apabila persamaan gelombang satu dimensi yang termuat dalam persamaan (8) digantikan dengan persamaan KdV, maka diperoleh persamaan KP yaitu:

$$
\partial_{x}\left[\partial_{t} \eta+c_{0}\left(\partial_{x} \eta+\frac{h^{2}}{6} \partial_{x}^{3} \eta\right)+\frac{3 c_{0}}{2 h} \eta \partial_{x} \eta\right]+\frac{c_{0}}{2} \partial_{y}^{2} \eta=0 .
$$

Persamaan (9) ini selanjutnya digunakan dalam penelitian ini untuk mengkaji perambatan gelombang dua dimensi.

\subsection{Penyelesaian Persamaan KP}

Persamaan KP yang dinyatakan dalam persamaan (9) akan diselesaikan menggunakan metode asimtotik hingga orde ke-3. Solusi dari persamaan (9) di bentuk sebagai deret pangkat dalam epsilon berikut

$$
\eta=\varepsilon \eta^{(1)}+\varepsilon^{2} \eta^{(2)}+\varepsilon^{3} \eta^{(3)}
$$

dengan $\eta=\eta(\theta), \theta=k x+l y-\omega t$.

Dengan menggunakan solusi (10) akan menghasilkan resonansi pada orde ke-3 yang menyebabkan semakin bertambahnya amplitudo seiring berjalannya waktu. Hal tersebut tidak sesuai dengan kondisi gelombang sesungguhnya. Oleh karena itu, untuk menghindari resonansi yang terjadi digunakan metode Linstead Poincare yaitu dengan mengekspansikan bilangan gelombang sebagai deret pangkat dalam $\varepsilon$ sehingga dalam solusi persamaan (10), bilangan gelombang $k$ dan $l$ diberikan sebagai berikut

$$
\begin{aligned}
& k=k^{(0)}+\varepsilon k^{(1)}+\varepsilon^{2} k^{(2)} \\
& l=l^{(0)}+\varepsilon l^{(1)}+\varepsilon^{2} l^{(2)}
\end{aligned}
$$

Dengan mensubstitusikan (10), (11), (12) ke dalam persamaan (9) akan diperoleh tiga buah persamaan diferensial biasa untuk masing-masing orde dimana solusi orde ke-1 adalah

$$
\eta^{(1)}=a e^{i \theta}+c c
$$

dengan relasi dispersinya $\omega=c_{0} k^{(0)}-\frac{c_{0} h^{2}}{6}\left(k^{(0)}\right)^{3}+\frac{c_{0}}{2} \frac{\left(l^{(0)}\right)^{2}}{k^{(0)}}$.

Sementara itu, dengan substitusi solusi orde pertama (13) ke dalam persamaan orde ke dua, menghasilkan solusi orde ke-2 


$$
\eta^{(2)}=a_{2} e^{2 i \theta}+c c
$$

dengan $a_{2}=\frac{3}{2} \frac{a^{2}}{h^{3}\left(k^{(0)}\right)^{2}}$. Pada persamaan ke dua juga diperoleh nilai $\left(k^{(1)}, l^{(1)}\right)=0$.

Selanjutnya dengan mensubstitusikan solusi orde pertama (13) dan kedua (14) ke dalam persamaan orde ke tiga diperoleh solusi orde ke-3 yaitu

$$
\eta^{(3)}=a_{3} e^{3 i \theta}+c c
$$

dengan $a_{3}=\frac{27}{16} \frac{a^{3}}{h^{6}\left(k^{(0)}\right)^{4}}$. Pada persamaan orde ke tiga ini juga diperoleh nilai koreksi bilangan gelombang $k^{(2)}$ dan $l^{(2)}$ yang memenuhi persamaan

$$
\left(-c_{0} k^{(0)}+\frac{c_{0} h^{2}}{2}\left(k^{(0)}\right)^{3}+\frac{c_{0}}{2} \frac{\left(l^{(0)}\right)^{2}}{k^{(0)}}\right) k^{(2)}-c_{0} l^{(0)} l^{(2)}=\frac{9 c_{0}}{4} \frac{a^{2}}{h^{4}} .
$$

Dengan demikian, diperoleh penyelesaian asimtotik persamaan KP yaitu

$$
\eta=a e^{i \theta}+\frac{3}{2} \frac{\left(k^{(0)}\right)^{2} a^{2}}{h^{3}\left(k^{(0)}\right)^{4}} e^{2 i \theta}+\frac{27}{16} \frac{a^{3}}{h^{6}\left(k^{(0)}\right)^{4}} e^{3 i \theta}+c c .
$$

\subsection{Pengaruh Frekuensi terhadap Bilangan Gelombang}

Bagian ini memberikan gambaran hubungan antara bilangan gelombang $l$ dan $k$ yang memenuhi asumsi untuk beberapa frekuensi $\omega$ yang diambil. Menurut asumsi yang diberikan pada persamaan KP, bilangan gelombang $l$ jauh lebih kecil dari bilangan gelombang $k$ yaitu $l<<k$. Oleh karena itu, beberapa frekuensi $\omega$ diambil sebagai simulasi. Pada penelitian ini frekuensi $\omega$ diambil sebagai berikut 1/detik; 1,33/detik; 1,6/detik; 2,1/detik; dan 2,5/detik.

Grafik yang menghubungkan antara bilangan gelombang $k$ dan $l$ untuk beberapa frekuensi $\omega$ diberikan oleh Gambar 1. Dari Gambar 1, kelima grafik menunjukkan bahwa nilai $k$ memiliki keterbatasan, artinya untuk setiap nilai $k$ tidak selalu $l<<k$ dengan $\omega$ tertentu. Keterbatasan tersebut dapat dilihat pada $\omega=2,1 /$ detik dan $k \geq 0,5 / \mathrm{m}$ maka yang memenuhi $l>0,5 / \mathrm{m}$. Demikian juga untuk $\omega=1,6 /$ detik dan $k=0,5 / \mathrm{m}$ maka yang memenuhi $l=0,499 \approx 0,5 \mathrm{~m}$. Dari keempat kasus $\omega$ yang diambil maka adalah $\omega=1,33 /$ detik adalah $\omega$ terbaik karena dengan $\omega$ tersebut terdapat lebih banyak pilihan nilai $l$ dan $k$ yang memenuhi asumsi.

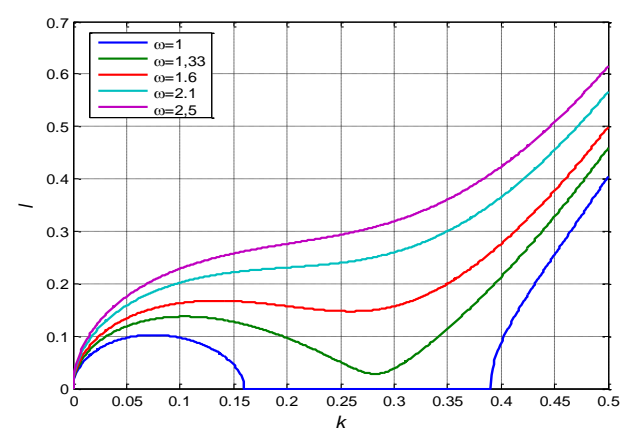

Gambar 1.Hubungan antara bilangan gelombang $k$ dan $l$ untuk beberapa frekuensi. Selanjutnya akan dipilih nilai $k=0,4 / \mathrm{m}$ dan $l=0,2 / \mathrm{m}$ untuk melihat penjalaran gelombang dengan frekuensi 1,33/detik. 


\subsection{Simulasi Persamaan KP dengan Metode Asimtotik}

Pada bagian ini, akan dilakukan simulasi terhadap solusi tiap orde metode asimtotik persamaan KP yaitu persamaan (14), (15), (16), dan solusi totalnya yaitu persamaan (17). Parameter yang diambil adalah kedalaman $h=5 \mathrm{~m}$ dan $a=0,04 \mathrm{~m}$. Solusi masing-masing orde diberikan dalam Gambar 2. Demikian juga solusi total dalam bentuk tiga dimensi dengan $t=0$ diberikan. Gambar 3 merupakan arah rambat dari gelombang monokromatik yang terjadi dengan parmeter-parameter tersebut.
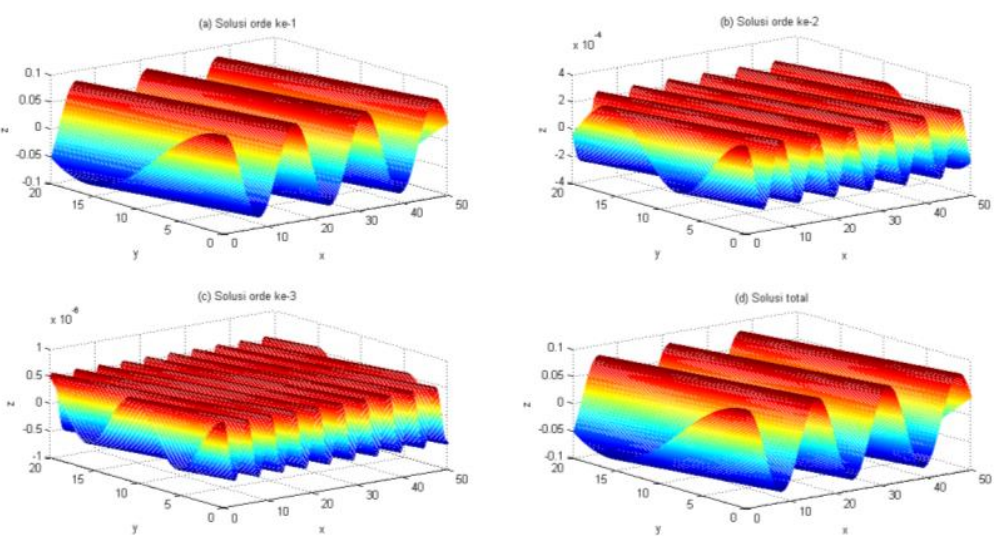

Gambar 2. Solusi tiap orde dalam bentuk 3 dimensi dengan $t=0$.

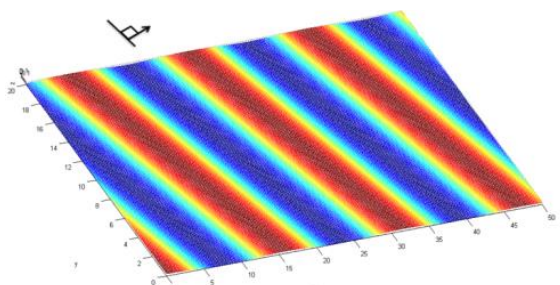

Gambar 3. Arah perambatan gelombang untuk solusi total

Selanjutnya, Gambar 4 yang menunjukkan gambar tiga dimensi posisi gelombang yang dominan berjalan ke arah $x$ positif atau gelombang saat $l=0$. Gambar 5 menunjukkan perambatan gelombang dari Gambar 4 pada bidan $x$ dan $\mathrm{z}$.
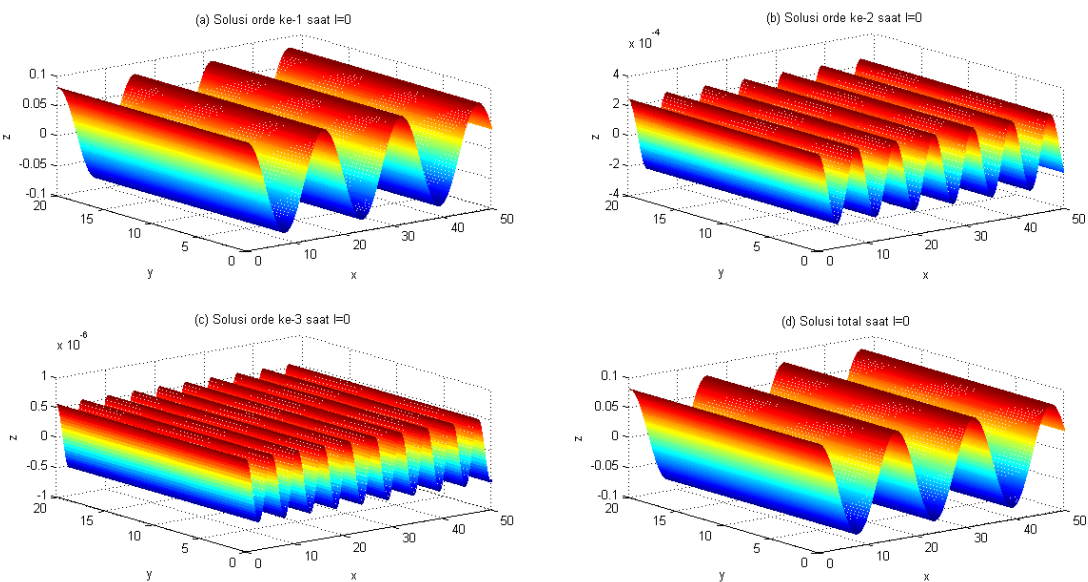

Gambar 4. Kurva 3 dimensi solusi tiap orde dengan $l=0$ 

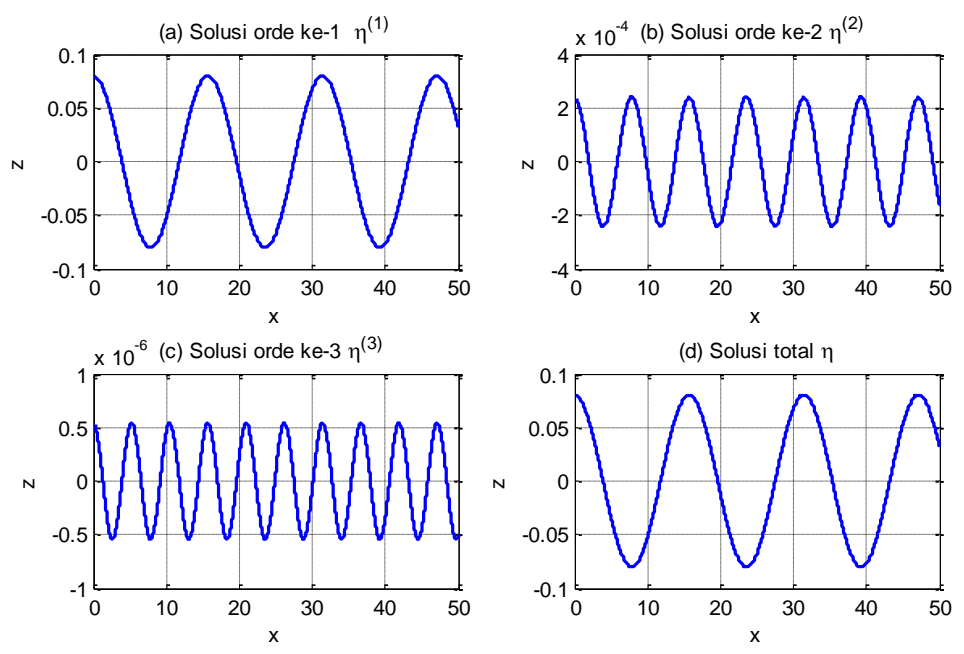

Gambar 5. Kurva solusi tiap orde dilihat dari sumbu $x$ dan $z$

Gmbar 5(a) merupakan solusi orde ke-1 yang memperlihatkan gelombang dengan amplitudo $0,08 \mathrm{~m}$ merambat sepanjang sumbu $x$ dari 0 sampai $50 \mathrm{~m}$ ditempuh 3,18 gelombang dengan panjang gelombangnya yaitu $15,7 \mathrm{~m}$. Gambar 5(b) merupakan solusi orde ke-2 yang memperlihatkan gelombang dengan amplitudo $0,00024 \mathrm{~m}$ merambat sepanjang sumbu $x$ dari 0 sampai $50 \mathrm{~m}$ ditempuh 6,37 gelombang dengan panjang gelombangnya yaitu 7,85 $\mathrm{m}$. Amplitudo solusi orde ke-2 lebih kecil dari solusi orde ke-1. Kemudian Gambar 5(c) merupakan solusi orde ke-3 yang memperlihatkan gelombang dengan amplitudo 0,00000054 m merambat sepanjang sumbu $x$ dari 0 sampai $50 \mathrm{~m}$ ditempuh 9,56 gelombang dengan panjang gelombangnya yaitu $5,23 \mathrm{~m}$. Solusi orde ke-3 memiliki amplitudo yang lebih kecil daripada solusi orde ke-2. Gambar 5(d) memperlihatkan solusi total yaitu jumlahan dari solusi orde ke-1 sampai orde ke-3. Pada solusi ini gelombang dengan amplitudo $0,08024 \mathrm{~m}$ merambat sepanjang sumbu $x$ dari 0 sampai $50 \mathrm{~m}$ ditempuh 3,18 gelombang dengan panjang gelombangnya yaitu $15,7 \mathrm{~m}$.

Berikut diberikan simulasi gelombang pada waktu tertentu yaitu saat $t=0$ detik, $t=10$ detik, $t=60$ detik, dan $t=1200$ detik.
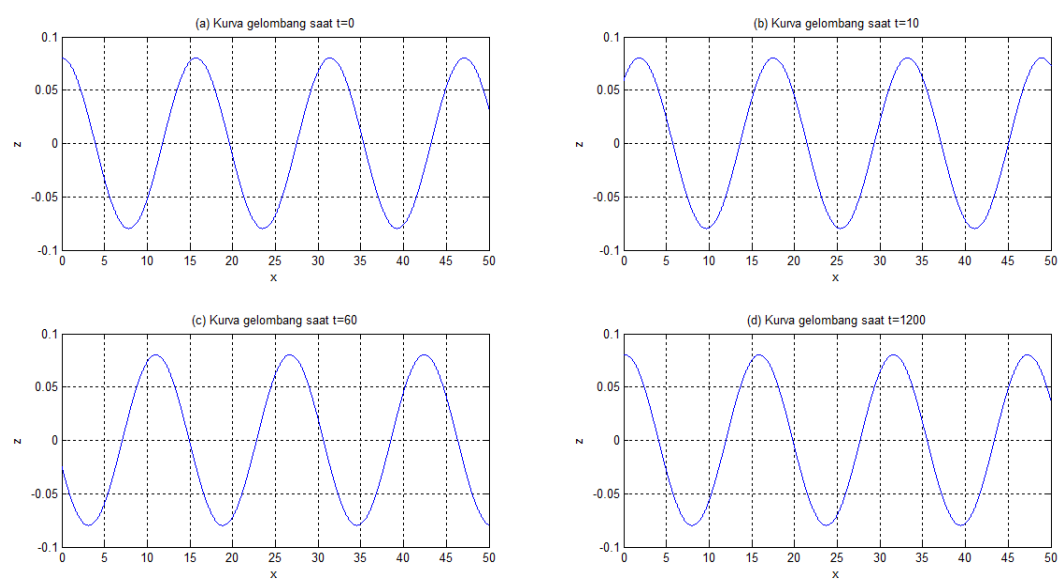

Gambar 6. Kurva gelombang saat $t$ tertentu

Gambar 6 menunjukkan bahwa kurva gelombang saat $t=0$ detik, $t=10$ detik, $t=60$ detik, dan $t=1200$ detik memiliki amplitudo yang sama. Dengan kata lain, seiring berjalannya waktu gelombang akan merambat dengan amplitudo yang tetap yaitu $0,08024 \mathrm{~m}$. 
Simulasi berikut menunjukan gelombang monokromatik dengan posisi $(x, y)$ tertentu. Sinyal gelombang monokromatik dengan $a=0,04 \mathrm{~m}$ dan frekuensi 1,33/detik. di setiap kurva sepanjang gelombang merambat disajikan pada Gambar 7.
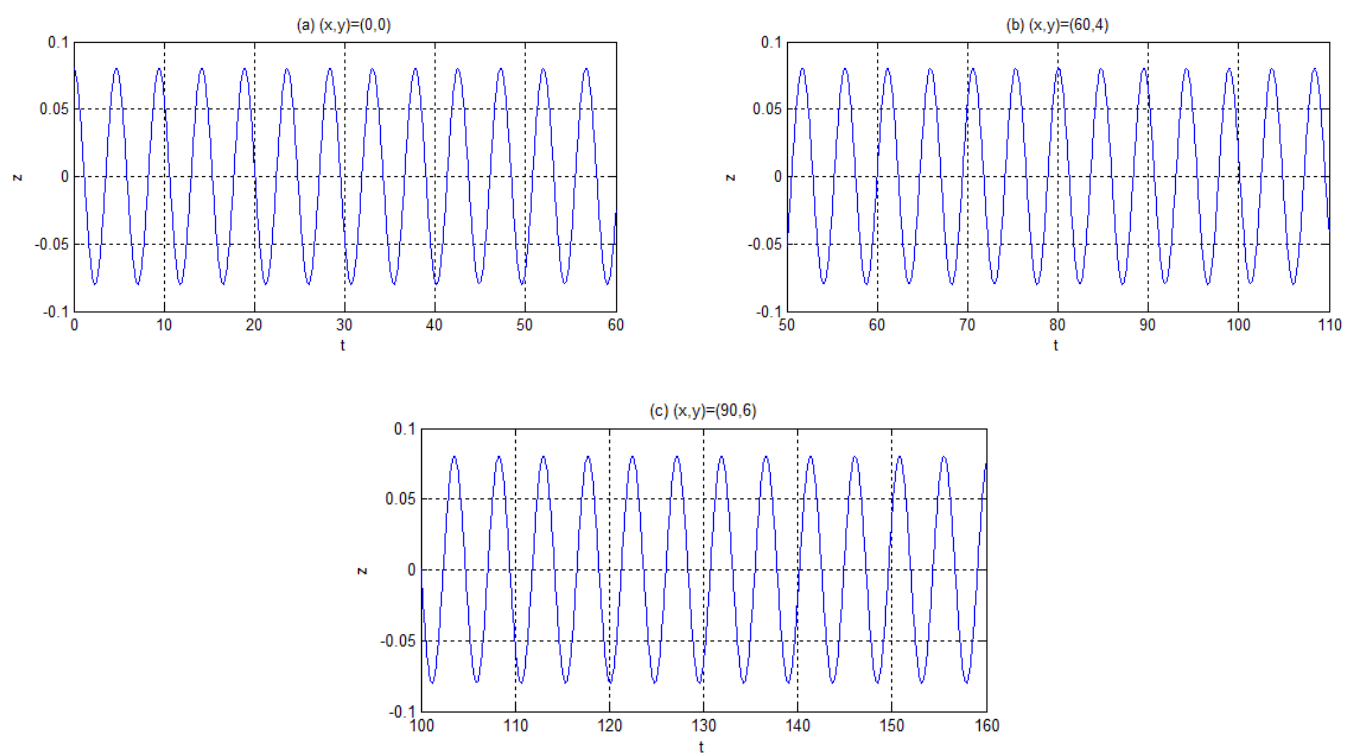

Gambar 7. Sinyal gelombang monokromatik dengan $a=0,04 \mathrm{~m}$ dan $\omega=1,33 /$ detik

Berdasarkan Gambar 7 (a) sinyal di posisi awal $(x, y)=(0,0)$ berbentuk sinyal monokromatik dengan amplitudo 0,08 $\mathrm{m}$. Sinyal ini merambat dengan amplitudo yang tetap.Begitu juga untuk gambar 7(b) dan gambar 7 (c) ketika disajikan sinyal di posisi $(x, y)=(60,4)$ dan $(x, y)=(90,6)$ amplitudo tetap dalam perambatannya. Dengan demikian dapat disimpulkan apabila disajikan sinyal pada posisi $(x, y)$ maka gelombang akan merambat dengan amplitudo yang tetap.

\section{Simpulan}

1. Persamaan KP atau yang biasa disebut dengan dua dimensi dari persamaan KdV dinyatakan dalam persamaan

$$
\partial_{x}\left[\partial_{t} \eta+c_{0} \partial_{x} \eta+\frac{c_{0} h^{2}}{6} \partial_{x}^{3} \eta+\frac{3 c_{0}}{4 h} \partial_{x}\left(\eta^{2}\right)\right]+\frac{c_{0}}{2} \partial_{y}^{2} \eta=0,
$$

mempunyai penyelesaian asimtotik sampai orde ke-3 yaitu

$$
\eta=a e^{i \theta}+\frac{3}{2} \frac{\left(k^{(0)}\right)^{2} a^{2}}{h^{3}\left(k^{(0)}\right)^{4}} e^{2 i \theta}+\frac{27}{16} \frac{a^{3}}{h^{6}\left(k^{(0)}\right)^{4}} e^{3 i \theta}+c c,
$$

dengan relasi dispersinya yaitu $\omega=c_{0} k^{(0)}-\frac{c_{0} h^{2}}{6}\left(k^{(0)}\right)^{3}+\frac{c_{0}}{2} \frac{\left(l^{(0)}\right)^{2}}{k^{(0)}}$.

2. Relasi dispersi persamaan KP yang mengandung persamaan KdV klasik memiliki keterbatasan yaitu tidak semua frekuensi memenuhi asumsi $l<<k$. Penyelesaian asimtotik persamaan KP dengan inputnya adalah gelombang monokromatik diperoleh kesimpulan bahwa gelombang merambat dengan bentuk sinusoidal yang amplitudonya tidak berubah.

\section{Ucapan Terima Kasih}


Penelitian ini merupakan bagian dari penelitian yang didanai oleh Kemenristek DIKTI dengan nomer kontrak : Nomor DIPA -042.06-0/2016. Penulis mengucapkan terimakasih kepada Kemenristek DIKTI yang telah mendukung terlaksananya penelitian ini.

\section{Daftar Pustaka}

1. Chaohao, G. (1995). Soliton Theory and Its Applications. New York: Springer.

2. Debnath, L. (1994). Nonlinear Water Waves. USA: Academic Press.

3. Jati, B. M. E., dan Priyambodo, T. K. (2008). Fisika Dasar untuk Ilmu-ilmu Eksakta dan Teknik. Yogyakarta: CV Andi Offset.

4. Liam, L. S., dan Groesen, E. V. (2010). Variational Derivation of Improved KP-type of Equations. Physics Letters A 374, 411-415.

5. Marwan. (2006). Gelombang Permukaan Satu dan Multi Arah Teori, Numerik, dan Aplikasinya pada Pembangkitan Gelombang Ekstrim. Disertasi S3, Departemen Matematika ITB, Bandung.

6. Mashuri dan Marwan. (2011). On The Near Third Order Asymptotic Solution of KdV and Boussineq Equations. Jurnal Natural. Vol 11, No. 1, FMIPA Unsyiah, Aceh 